\title{
Correction to: Conscious Ergonomics in Architecture: Energy, Matter, and Form from Theory to Practice
}

\author{
María Araya León (D), Ricardo Guasch, Alberto T. Estévez (D), \\ and Javier Peña
}

\section{Correction to:}

Chapter "Conscious Ergonomics in Architecture: Energy, Matter, and Form from Theory to Practice"

in: N. L. Black et al. (Eds.): Proceedings of the 21st Congress

of the International Ergonomics Association (IEA 2021),

LNNS 221, https://doi.org/10.1007/978-3-030-74608-7_37

The original version of the book was inadvertently published with error as "EGG and Menez", and this has been corrected as "EEG and Mendez" in Page "299" of Chapter "Conscious Ergonomics in Architecture: Energy, Matter, and Form from Theory to Practice". 